lem of medical management. Maintenance treatment with moderate doses of corticosteroids is completely ineffective as well as carrying the risks of long-term corticosteroid administration (Truelove and Witts, 1959; Lennard-Jones et al., 1965). By contrast, sulphasalazine has emerged as an effective agent for maintenance treatment. Though it is not universally successful it nevertheless reduces the recurrence rate to about a quarter of that experienced by control groups, and this suppressive effect is sustained during maintenance treatment for at least five years (Misiewicz et al., 1965; Dissanayake and Truelove, 1973). Our results show that azathioprine does not exert such a powerful suppressive action as sulphasalazine, which remains the most important medical agent for maintenance treatment.

If azathioprine has any place in the medical treatment of ulcerative colitis it is as maintenance treatment in patients who have failed to do well on conventional treatment with corticosteroids and sulphasalazine and in whom there is some good reason for not performing or deferring proctocolectomy. If azathioprine is used close supervision is necessary because of the risk of bone-marrow suppression and hepatic toxicity. Possibly also azathioprine predisposes to subsequent neoplasia though decisive evidence is not yet available outside the field of organ transplantation (British Medical fournal, 1973).

We thank Dr. A. H. Griffith of the Wellcome Foundation for his co-operation, including the supply of trial tablets. Dr. R. Whitehead classified the biopsy specimens, Drs. A. C. Campbell and I. C. M. MacLennan made the immunological investigations, and Dr. J. M. Skinner made quantitative studies on immunocytes in biopsy specimens.

\section{References}

Campbell, A. C., et al. (1974). Clinical and Experimental Immunology, 16, 521. Dissanayake, A., S and Truelove, S C (1973), Gut, 14,923.

Jewell, D. P., and Truelove, S. C. (1972). British Medical fournal, 1, 709.

Jewell, $P$., and Truelove, S. C. (1972

British Medical fournal (1972). 3, 713 .

Lennard-Jones, J. E., et al. (1965). Lancet, 1, 188.

Misiewicz, J. J., et al. (1965). Lancet, $1,185$.

ruelove, S. C., and Richards, W. C. D. (1956). British Medical fournal, 1, 1315 .

Truelove, S. C., and Witts, L. J. (1955). British Medical Fournal, 2, 1041.

Truelove, S. C., and Witts, L. J. (1959). British Medical fournal, $1,387$.

\title{
Longitudinal Study of Untreated Chemical Diabetes
}

\author{
A. W. LOGIE, J. M. STOWERS, I. DINGWALL-FORDYCE
}

British Medical fournal, 1974, 4, 630-632

\begin{abstract}
Summary
More information is needed about the "natural history" of early diabetes mellitus. A report is presented of the progress over one to nine years of 72 patients who formed the control group of a clinical trial of chlorpropamide and placebo in the management of subclinical diabetes. Most patients showed no deterioration of carbohydrate tolerance, and only four (5.6\%) progressed to overt diabetes. The findings of other published series are reviewed. Studies of the effect of treatment of early diabetes must be large scale and long term, and an untreated control group must be included to prevent apparent improvement in carbohydrate tolerance being wrongly attributed to the effect of therapy.
\end{abstract}

\section{Introduction}

Surprisingly little is known about the natural history of untreated subclinical diabetes mellitus. It is widely assumed that progression to overt diabetes will occur, and while it is known that such deterioration may be rapid or very slow (Marble, 1971) information is lacking on several aspects of early diabetes. An uncontrolled clinical trial of the long-term effect of chlorpropamide in subclinical diabetes (Stowers and Helgason, 1965; Stowers, 1973) has shown improvement of carbohydrate tolerance to normal in some groups of patients, especially those below the age of 35 years. Possibly this is due to the $\beta$-cytotrophic effect of the sulphonylureas which has been clearly shown in animals (Loubatières et al., 1956). Results of the uncontrolled

Diabetic Clinic, Aberdeen Royal Infirmary, Aberdeen AB9 1GS A. W. LOGIE, M.B., M.R.C.P., Senior Registrar

J. M. STOWERS, M.D., F.R.C.P., Consultant Physician

Department of Community Medicine, University of Aberdeen, Aberdeen

I. DINGWALL-FORDYCE, Research Officer trial emphasized the obvious need for a long-term trial to include an untreated control group. A double-blind, controlled, clinical trial to compare the effect of chlorpropamide and placebo in subclinical diabetes was therefore established in 1963 under the auspices of the British Diabetic Association (B.D.A.). We report here on the progress of the placebo-treated control group of chemical diabetics (see B.D.A. classification of diabetes, FitzGerald and Keen, 1964).

\section{Method}

Patients who had given their informed consent were admitted to the trial if, on testing with an intravenous glucose tolerance test (I.V.G.T.T.), they were shown to have chemical, asymptomatic diabetes-that is, a normal fasting blood sugar level but an abnormal curve thereafter. The original screening was made because of asymptomatic glycosuria, a strong family history of diabetes, "temporary" diabetes within the previous 10 years, or reproductive performance resulting in a baby over 4,500 $\mathrm{g}$ at birth, a stillborn infant with islet cell hyperplasia of pancreas not due to rhesus incompatibility, 10 or more chidren, two or more "unexplained" stillbirths, or excessive weight gain during pregnancy. Since the trial was designed in 1963 we have refined the selection criteria-for example, by defining a significantly overweight baby as one above the 95th percentile weight for gestation and maternal weight (Thomson et al., 1968). For admission to this part of the trial the body weight of all patients had to be within the 75th percentile for age, sex, and height (after Kemsley, 1951-2). Allocation to the active drug or placebo group was randomized. Patients were reviewed at least twice yearly and had an annual I.V.G.T.T., stopping tablets for three weeks before the test to obviate any immediate pharmacological effect on the I.V.G.T.T. in those patients on the active drug. Blood sugar estimations were done on capillary specimens by the AutoAnalyzer ferricyanide method (Hoffman, 1937).

A.W.L. broke the randomization code and studied the 72 placebo-treated patients ( 38 women, $34 \mathrm{men}$ ) who had been in the trial for at least one year (mean 4.2 years). Their ages at the time of entry ranged from 19-54 years (mean $39 \cdot 7$ years). 
Originally, entry to the trial was restricted to people of $35-55$ years as we thought that this age group would incorporate the period of expected peak incidence of overt diabetes. The previously mentioned, uncontrolled, clinical trial of chlorpropamide in subclinical diabetes (Stowers and Helgason, 1965; Stowers, 1973), however, has shown a tendency to greater improvement in younger people than in older ones, so the lower age limit of 35 years was dropped in 1967. The initial restriction on age at entry explains why the long-duration subjects of the present series are all in the older age groups (see table II).

Sequential increment indices for the whole group have been analysed, and in smaller cohorts the fasting blood sugar levels and body weights have also been examined.

\section{Results}

The mean differences from the initial increment index values for the whole group are shown in table I by age at the time of the examination. In all age groups there was an improvement from the initial value. A more detailed cohort analysis of a subgroup of 27 patients is shown in table II. All those under 35 in this subgroup had been in the trial for at least three years, and all those in the older age groups had been in for at least seven years.

With regard to the increment indices the standard deviation of all the measurements was large and none of the differences was statistically significant so interpretation must be guarded. There was a steady trend, however, to improvement in all groups, the reverse of what might have been expected.

Details of the 17 patients withdrawn from the survey are given in table III. Their results have been included in the analysis until the time of their withdrawal. Of the 72 patients only four $(5.6 \%)$ developed overt diabetes, and only six others $(8.3 \%)$ after four to nine years in the trial showed a consistent trend to deterioration of carbohydrate tolerance while maintaining a normal fasting blood sugar.

TABLE I-Mean Difference ( $\pm S . D$.) from Initial Increment Index Values in Three Age Groups. Numbers in Brackets are Total Number of Patients in Each Category for Each Year

\begin{tabular}{c|c|c|c}
\hline \multirow{2}{*}{ Years since Entry } & \multicolumn{2}{|c}{ Age at Time of Examination (Years) } \\
\cline { 2 - 4 } \cline { 3 - 4 } & $<35$ & $35-44$ & $\geqslant 45$ \\
\hline 1 & $0.84 \pm 1.04(15)$ & $1.08 \pm 1.29(30)$ & $0.43 \pm 1.00(27)$ \\
2 & $1.20 \pm 0.82(9)$ & $1.07 \pm 1.07(20)$ & $0.42 \pm 1.22(25)$ \\
3 & $0.16 \pm 1.47(4)$ & $1.11 \pm 2.16(14)$ & $0.53 \pm 1.11(29)$ \\
4 & & $0.79 \pm 0.88(9)$ & $0.99 \pm 1.06(24)$ \\
5 & & $1.31 \pm 1.22(7)$ & $0.93 \pm 1.31(22)$ \\
6 & & $1.41 \pm 2.25(5)$ & $0.72 \pm 1.29(18)$ \\
7 & & & $0.76 \pm 1.23(19)$ \\
8 & & & $0.79 \pm 1.32(13)$ \\
9 & & & $0.77 \pm 1.40(5)$ \\
\hline
\end{tabular}

TABLE II-Cohort Analysis of 27 Patients with Chemical Diabetes

\begin{tabular}{|c|c|c|c|}
\hline Years since Entry & $\begin{array}{c}\text { Mean } \\
\text { Increment Index* } \\
\text { Value }( \pm \text { S.D. })\end{array}$ & $\begin{array}{l}\text { Mean Fasting } \\
\text { Blood Sugar } \\
\text { (mg/100 ml) } \\
( \pm \text { S.D. })\end{array}$ & $\begin{array}{l}\text { Mean Weight } \\
(\mathbf{k g})( \pm \text { S.D. }\end{array}$ \\
\hline $\begin{array}{l}0 \\
1 \\
2 \\
3\end{array}$ & \multicolumn{2}{|c|}{\begin{tabular}{l|r}
\multicolumn{2}{c}{ Patients under 35 years $(n=6)$} \\
$2 \cdot 2 \pm 0.43$ & $79 \pm 16.2$ \\
$3.2 \pm 0.80$ & $85 \pm 13.9$ \\
$3.7 \pm 1.04$ & $81 \pm 8.2$ \\
$2.7 \pm 1.40$ & $82 \pm 16.9$
\end{tabular}} & $\begin{array}{l}59 \cdot 4 \pm 7 \cdot 9 \\
59 \cdot 0 \pm 8 \cdot 4 \\
62 \cdot 6 \pm 9 \cdot 4\end{array}$ \\
\hline $\begin{array}{l}0 \\
1 \\
2 \\
3 \\
4 \\
5 \\
6 \\
7\end{array}$ & $\begin{array}{l}2.3 \pm 0.44 \\
3.1 \pm 0.99 \\
3.1 \pm 0.76 \\
2 \cdot 6 \pm 0.64 \\
3.2 \pm 0.92 \\
3.2 \pm 1 \cdot 01 \\
3.5 \pm 1.72 \\
3.1 \pm 0.84\end{array}$ & $\begin{array}{l}72 \pm 11.3 \\
81 \pm 11.5 \\
85 \pm 9 \cdot 6 \\
87 \pm 15 \cdot 6 \\
89 \pm 14.8 \\
90 \pm 17.7 \\
84 \pm 14 \cdot 2 \\
92 \pm 16.0\end{array}$ & $\begin{array}{l}64 \cdot 4 \pm 7 \cdot 2 \\
64 \cdot 4 \pm 7 \cdot 2 \\
65 \cdot 3 \pm 10 \cdot 2 \\
65 \cdot 3 \pm 9 \cdot 3 \\
65 \cdot 3 \pm 8 \cdot 9 \\
67 \cdot 1 \pm 10 \cdot 4 \\
67 \cdot 6 \pm 10 \cdot 4 \\
68 \cdot 0 \pm 10 \cdot 9\end{array}$ \\
\hline $\begin{array}{l}0 \\
1 \\
2 \\
3 \\
4 \\
5 \\
6 \\
7\end{array}$ & $\begin{array}{l}2.3 \pm 0.64 \\
2.3 \pm 0.37 \\
2.4 \pm 0.77 \\
2.8 \pm 0.92 \\
3.5 \pm 0.73 \\
3.4 \pm 1.18 \\
3.1 \pm 0.89 \\
3.3 \pm 1.14\end{array}$ & $\begin{array}{l}r s(n=11) \\
75 \pm 7 \cdot 1 \\
83 \pm 7 \cdot 0 \\
73 \pm 13 \cdot 4 \\
78 \pm 12 \cdot 0 \\
85 \pm 11 \cdot 9 \\
82 \pm 16 \cdot 4 \\
82 \pm 13.9 \\
90 \pm 14 \cdot 3\end{array}$ & $\begin{array}{l}67 \cdot 6 \pm 7 \cdot 1 \\
65 \cdot 3 \pm 7 \cdot 3 \\
65 \cdot 8 \pm 8 \cdot 4 \\
66 \cdot 7 \pm 7 \cdot 7 \\
65 \cdot 8 \pm 8 \cdot 2 \\
65 \cdot 8 \pm 8 \cdot 2 \\
64 \cdot 4 \pm 7 \cdot 9 \\
65 \cdot 8 \pm 8 \cdot 5\end{array}$ \\
\hline
\end{tabular}

* Normal increment index values: $>2.96$
TABLE III-Reasons for Withdrawal from Study in 17 Patients

\begin{tabular}{|c|c|c|c|c|}
\hline Reason & $\begin{array}{l}\text { No. of } \\
\text { Patients }\end{array}$ & $\begin{array}{l}\text { Age at } \\
\text { Time of } \\
\text { Event }\end{array}$ & $\begin{array}{l}\text { No. of } \\
\text { Years } \\
\text { in Trial }\end{array}$ & Comments \\
\hline$\overline{\text { Died }}$ & 1 & 58 & 4 & $\begin{array}{l}\text { Died of myocardial infarction; } \\
\text { severe M.I. } 7 \text { years previously; } \\
\text { carbohydrate tolerance had } \\
\text { remained normal }\end{array}$ \\
\hline Overt diabetes & 4 & $\begin{array}{l}37,41 \\
45,45\end{array}$ & $1,3,3,3$ & $\begin{array}{l}\text { All subsequently well controlled on } \\
\text { sulphonylurea, one with addition } \\
\text { of metformin, } 9 \text { yr., } 7 \mathrm{yr} \text {., and } \\
3 \text { yr. later respectively }\end{array}$ \\
\hline $\begin{array}{l}\text { Symptoms } \\
\text { attributed by } \\
\text { patient to tablets }\end{array}$ & 1 & 36 & 2 & $\begin{array}{l}\text { Worry over weight loss of } 4.5 \mathrm{~kg} \\
\text { in } 1 \text { year }\end{array}$ \\
\hline $\begin{array}{l}\text { Hypoglycaemia } \\
\text { during } \\
\text { I.V.G.T.T. }\end{array}$ & 1 & 40 & 2 & $\begin{array}{l}\text { Blood sugar fell to } 38 \mathrm{mg} \text { and } \\
40 \mathrm{mg} / 100 \mathrm{ml} \text { at } 40 \text { and } 50 \mathrm{~min} \text {. } \\
\text { respectively; no subsequent } \\
\text { symptoms; I.V.G.T.T. } 5 \mathrm{yr} \text {. }\end{array}$ \\
\hline Moved from & 3 & & $4,2,1$ & \\
\hline Uncooperative & 6 & & $\begin{array}{l}4,3,2 \\
1,1,1\end{array}$ & $\begin{array}{l}\text { Failure to attend or to take } \\
\text { tablets regularly as detected by } \\
\text { negative fluorescein test result } \\
\text { in urine (Thompson and }\end{array}$ \\
\hline $\begin{array}{l}\text { Excessive } \\
\text { weight gain }\end{array}$ & 1 & 45 & 1 & $\begin{array}{l}\text { Transferred to another group in } \\
\text { trial }\end{array}$ \\
\hline
\end{tabular}

Fasting blood sugar levels in the two older age groups (table II) tended to increase with time, and this held true for the whole population, but the standard deviation was large and the figures fell short of statistical significance. Body weights in both subgroup and the whole group remained nearly constant.

\section{Discussion}

This longitudinal study of the progress of 72 untreated chemical diabetics over a period of one to nine years failed to show significant deterioration of carbohydrate tolerance in most patients. Only four patients progressed to overt diabetes and a further six showed a consistent fall on the increment index while retaining a normal fasting blood sugar level.

From the large and confusing variety of tests and criteria for the diagnosis of early diabetes (O'Sullivan and Mahan, 1968) the I.V.G.T.T. was chosen. There is no ideal diagnostic test for diabetes, and most workers prefer the oral test (Olefsky et al. 1973) though it is widely recognized as being poorly reproducible (McDonald et al., 1965). The I.V.G.T.T. has been shown to be reproducible in the short term (Duncan, 1956), and it yields figures, the absolute $(K)$ or increment index, which facilitate direct statistical comparison of sequential tests. We believe that the increment index is preferable to the $\mathrm{K}$ index because foe mild degrees of carbohydrate intolerance where fasting levslr are normal the increments above fasting, rather than the absolute levels themselves, give a better fit to an exponential line (Medley, 1965).

Diabetes is a progressive condition, and it has seemed reasonable to hope that early detection and treatment would help prevent the onset or delay the progression of its many recognized complications (Conn, 1958). This hope has provided the rationale for the many detection campaigns which have been carried out (e.g., Wilkerson and Krall, 1947, 1953; Ostrander et al., 1965; Sharp, 1964; College of General Practitioners, 1962, 1963). The philosophy and value of presymptomatic diagnosis of diabetes have been well stated by Keen (1966).

Several studies have now been published of early diabetes and of the effect of treatment on its progression. O'Sullivan and Mahan (1968) found progression to overt diabetes in 9.5\%$25.9 \%$ of a sample of 352 female chemical diabetics aged 21-50 years on entry followed for one to 12 years. The variation in incidence arose from the application of different diagnostic criteria of diabetes. Using actuarial life table techniques (not applicable to our survey because of smaller numbers) they calculated that had the whole sample been followed for 12 years $21 \%-52 \%$ would have developed overt diabetes.

Fajans et al. (1973) followed 45 chemical diabetics aged 9-25 years at diagnosis and found that four $(8.9 \%)$ progressed to 
insulin dependency over one to 16 years. Rosenbloom et al. (1973) put together the results of nine separate series (including that of Fajans et al. (1973)) of chemical diabetics, which gave a total of 214 "children" followed for up to 17 years. During this time only $22(10.3 \%)$ had progressed to insulin dependency. Many of these patients had been treated with sulphonylurea.

Feldman et al. (1973) have reported on 83 chemical diabetics, aged 15-29 years on entry to their trial, who were treated with placebo for up to five-and-a-half years (mean 20 months). Only three $(3.6 \%)$ of these people developed overt diabetes.

Hoffman and Jackson (1974) in a separate part of this B.D.A. trial have found that of 10 chemical diabetics, aged 31-50 years and treated with placebo for one to eight years (mean $5 \cdot 1$ years), three developed overt diabetes. They also studied 19 potential* diabetics aged 35-54 years for one to eight years (mean 6.8 years) and found that only one patient became a chemical diabetic.

Other published series have been of small numbers of patients, and most have been uncontrolled. Terminology is not standard; criteria both of selection of patients for study and of progression of diabetes have been variable and allocation to different treatment groups haphazard. Thus, direct comparison of different series is not valid. (Quoting percentages in studies of this type may give a falsely low impression of the true incidence of progression of carbohydrate intolerance since not all the patients have been followed for the total duration of the trial. Such percentages are quoted here, however, for ease of general comparison between series.) The proportion progressing to overt diabetes in our study was slightly lower than in most other groups, but most series have shown a relatively small incidence of deterioration of carbohydrate intolerance. Fajans et al. (1973) have repeatedly stressed that chemical diabetes can be detected by screening in young people who "may exhibit the non-progressive course of the carbohydrate intolerance of the maturity-onset type of diabetic."

The need for carefully designed, controlled, long-term studies of the efficacy of a particular form of treatment is clear and is emphasized by our study, in which a much lower proportion $(5.6 \%)$ of untreated patients progressed to overt diabetes than we expected. Without this knowledge it would have been very tempting to attribute any improvement or lack of deterioration in the treated group to the effect of therapy.

Details of the four patients in our series who progressed to overt diabetes are given in table III. In each case overt diabetes was diagnosed on biochemical rather than clinical grounds. No patient had primary symptoms of diabetes at this time or subsequently. None had any features of intercurrent illness which might have provoked a temporary deterioration, and there was no history of exposure to diabetogenic drugs. It is interesting that those patients in our series who developed overt diabetes had all been in the trial for a comparatively short time (three for three years and one for one year). Of the 10 chemical diabetics of Hoffman and Jackson (1974) two became overtly diabetic within one year. Their third patient became overtly diabetic after eight years, in association with an excessive weight gain of $16 \mathrm{lb}(7.25 \mathrm{~kg})$. Of their series of 19 potential diabetics the one patient who developed chemical diabetes gained $16 \mathrm{lb}$ $(7 \cdot 25 \mathrm{~kg})$ in 15 months.

Our study of the placebo-treated group cannot accurately be taken to reflect the true "natural history" of early diabetes since patients were given dietary advice about restriction of refined carbohydrate. On entry to the trial their body weights were all within the 75 th percentile, and they did not gain excess weight. All these factors would help to improve carbohydrate tolerance in chemical diabetes and may have been responsible, at least in part, for the absence of progression of carbohydrate intolerance in most of the patients. It is well known that obesity causes relative insulin resistance (Karam et al., 1963) that the hyperinsulinism of obese persons, both diabetic and

* Potential diabetics are persons of normal carbohydrate tolerance considered to be at high risk of developing diabetes (B.D.A. classification, FitzGerald and Keen, 1964). non-diabetic, falls with reduction in weight (El Khodary et al., 1972), and that insulin secretion drops with restriction of dietary refined carbohydrate in obese persons, even in the absence of weight loss (Grey and Kipnis, 1971). Jackson et al. (1972) have commented on the apparent efficacy of dietary measures and weight reduction in causing improvement to normal carbohydrate tolerance in 34 out of 40 people with "borderline" diabetes on retesting with the oral test after an interval of one year.

The University Group Diabetes Programme (Klimt et al., 1970; Knatterud et al., 1971) found increased mortality from cardiovascular causes in overt diabetics treated with oral antidiabetic agents compared with those treated by insulin therapy or diet alone. These results are supported by Hadden et al. (1972) and Soler et al. (1974) but are discordant with those of other workers (Keen et al., 1973; Paasikivi, 1973; Stowers, 1973; Feldman et al., 1973). The controversy adds a new dimension to the drug treatment of early diabetes and at the least emphasizes the need for great care with design and follow-up of such studies and for the inclusion of a control group.

A report on the progress of the whole trial will be prepared in due course, but it is expected, in the light of the unexpected lack of deterioration of most of the control group, that the trial may well have to continue for a further five years before statistically significant results can be expected to emerge. Liddle (1973) has forecast that studies such as these may have to run for as long as 30 years before a scientific conclusion can be reached.

We thank our patients for their active co-operation, the medical, nursing, and secretarial staff of the diabetic clinic for their help, and Pfizer Ltd. for providing the placebo tablets. Blood sugar estimations were done by the department of chemical pathology, University of Aberdeen.

\section{References}

College of General Practitioners. (1962). British Medical fournal, 1, 1497.

College of General Practitioners. (1963)

Conn, J. W. (1958). Diabetes, 7, 347. Duncan, L. J. P. (1956).Quarterly fournal of Experimental

Fajans, S. S., et al. (1973). Metabolism, Clinical and Experimental, 22, No. 2, 327

Feldman, R., et al. (1973). Advances in Metabolic Disorders, 2, Suppl. 2, 557. FitzGerald, M. G., and Keen, H. (1964). British Medical fournal, 1, 1568. Grey, N., and Kipnis, D. M. (1971). New England fournal of Medicine, 285, 827 .

Hadden, D. R., Montgomery, D. A., and Weaver, J. A. (1972). Lancet,, 1,335 .

Hoffman, M., and Jackson, W. P. U. (1974). Personal communication.

Hoffman, W. S. (1937). Fournal of Biochemistry, 120, 51.

Jackson, W. P. U., et al., (1972). South African Medical fournal, 46, 2065.

Karam, J. H., Grodsky, G. M., and Forsham, P. H. (1963). Diabetes, 12, 197. Karam, J. H., Grodsky, G. M., and Forsham, P. H. (1963). Diabetes, 12, 197. een, H. (1966). In Presymptomatic Deteciion and Early Diag
C. L. E. H. Sharp and H. Keen, p. 165. London, Pitman.

Keen, H., et al. (1973). Advances in Metabolic Disorders, 2, Suppl. 2, 521.

Kemsley, W. F. F. (1951-52). Annals of Eugenics, 16, 316.

Klimt, C. R., et al. (1970). Diabetes, 19, Supplement 2, 747 and 787.

Knatterud, G. L., et al. (1971). Fournal of the American Medical Association, 217,777 .

Liddle, G. W. (1973). Fournal of Endocrinology, 59, II.

Loubatières, A., Bouyard, P., and Fruteau de Laclos, C. (1956). Diabète, 4,38

McDonald, G. W., Fisher, G. F., and Burnham, C. (1965). Diabetes, 14, 473.

Marble, A. (1971). In Foslin's Diabetes Mellitus, ed. P. White, R. F. Bradley, and L. P. Krall, 11th edn., p. 5. Philadelphia, Lea and Febiger.

Medley, D. R. K (1965) Quarterly fournal of Medicine 34 ,

Olefsky, J. M., Farquhar, J. W., and Reaven, G. M (1973). Diabotes, 22, 202.

Olefsky, J. M., Farquhar, J. W., and Reaven, G. M (1973). Diabotes, 22, 202

O'Sullivan, J. B., and Mahan, C. M. (1968). New England fournal of Medicine, $78,1038$.

Paasikivi, J. (1973). Advances in Metabolic Disorders, 2, Suppl. 2, 533.

Rosenbloom, A. L., Drash, A., and Guthrie, R. (1973). Metabolism, Clinical and Experimental, 22, 413.

Sharp, C. L. (1964). Proceedings of the Royal Society of Medicine, 57, 193.

Soler, N. G., et al. (1974). Lancet, 1, 475.

Stowers, J. M., and Helgason, T. (1965). Diabetologia, 1, 128

Stowers, J. M. (1973). Advances in Metabolic Disorders, 2, Suppl. 2, 549.

Thompson, R. H., and Stowers, J. M. (1971). Scottish Medical fournal, 16, 259.

Thomson, A. M., Billewicz, W. Z., and Hytten, F. E. (1968). Fournal of Obstetrics and Gynaecology of the British Commonwealth, 75, 903.

Wilkerson, H. L. C., and Krall, L. P. (1947). Fournal of the American Medical Association, 135, 209.

Association, 135, 209.
Wilkerson, H. L. C., and Krall, L. P. (1953). Fournal of the American Medical Association, 152, 1322. 